\title{
Therapeutic Potential of Staphylococcal Bacteriophages for Nasal Decolonization of Staphylococcus aureus in Mice
}

\author{
Madhavi H. Narasimhaiah, Jiya Y. Asrani, Sundaram M. Palaniswamy, Jagadeesh Bhat, \\ Shilpa E. George, Rajamuthu Srinivasan, Aradhana Vipra, Srividya N. Desai, Raghu Patil Junjappa, \\ Panchali Roy, Bharathi Sriram, Sriram Padmanabhan* \\ Gangagen Biotechnologies Pvt. Ltd., Raghavendra Layout, Bangalore, India \\ Email: "sripad@gangagen.com
}

Received January 18, 2013; revised February 17, 2013; accepted March 8, 2013

\begin{abstract}
Bacteriophages represent a rich and unique resource of anti-infectives to counter the global problem of antibiotic resistance. In this work, we assessed the bactericidal activity of two virulent staphylococcal phages, $\mathrm{K}$ and $44 \mathrm{AHJD}$, against S. aureus isolates of clinical significance, and tested their efficacy in vivo. The phage cocktail lysed $>85 \%$ of the clinical isolates tested. Both the phages were purified by ion-exchange column chromatography following propagation in bioreactors. The purity profiles of the ion-exchange purified phages were compared with those of phages purified using cesium chloride density gradient ultracentrifugation, and infectiousness of the purified phages was confirmed by plaque forming assay. The in vivo efficacy of a phage cocktail was evaluated in an experimental murine nasal colonization model, which showed that the phage cocktail was efficacious. To our knowledge, this is the first report of phage use in an in vivo model of nasal carriage.
\end{abstract}

Keywords: Bacteriophage K; Nasal Decolonization; Phage 44AHJD; Phage Endotoxins; Phage Purification; Staphylococcus aureus

\section{Introduction}

During the last century, the human pathogen Staphylococcus aureus has become the main cause of nosocomial and community-acquired infections worldwide [1]. Both coagulase-negative Staphylococcus (CoNS) and coa- gulase-positive Staphylococcus (CoPS) cause serious infections, ranging from localized or systemic abscesses, septicemia, and endocarditis, to septic emboli and fatal sepsis [2]. After the introduction of methicillin in the early 1960 s, isolation of multi-resistant S. aureus strains was reported [2-4]. Methicillin-resistant S. aureus (MRSA) strains are becoming increasingly difficult to combat, mainly because of emerging resistance to all currently used antibiotics. In addition, the ability of staphylococcal species to produce a variety of toxins and to attach to medical devices by producing biofilms has compounded the problem $[4,5]$.

The emergence of MRSA in both hospital and community settings has prompted researchers to try to develop methods for the nasal decolonization of MRSA and methicillin-susceptible Staphylococcus aureus (MSSA) in specific patient groups. In the UK, it is recommended that MRSA carriers who are receiving prophylaxis for an

"Corresponding author. operation should undergo nasal decolonization with mupirocin, the most commonly used antibiotic for Grampositive bacteria [6]. Because nasal relapses are common within several months [7], and mupirocin resistant $S$. aureus strains have recently been reported [8], alternate treatments are being pursued by various groups.

Squalamine, a water-soluble natural polyaminosterol isolated from the tissues of the dogfish shark (Squalus acanthias), has a 10,000-fold higher antimicrobial activity towards S. aureus than mupirocin [9]. Interestingly, the use of a less virulent Staphylococcus strain (S. epidermidis) to block colonization by pathogenic $S$. aureus strains has also been reported $[10,11]$.

The effectiveness of bacteriophages for phage therapy against pathogenic bacteria in both animals and humans is well documented [12]. Because they are present in all environments, including water, soil, and air, and are highly specific and lethal to their target host [13], bacteriophages are attractive therapeutic agents for combatting life-threatening bacterial infections in humans and animals. The safety and efficacy of phages has been supported by extensive clinical use of phages in eastern European countries, including the former Soviet Union [14]. The success of phage therapy against various oral, topical, and systemic bacterial infections without the need 
for genetic manipulation has been well documented [15, $16]$.

It is generally accepted that virulent phages are more suitable candidates for therapeutic applications than temperate phages. The complications associated with temperate phages, such as super-infection immunity and possibility of integration into the host genome (lysogeny), and the possibility of transfer of genetic material, such as drug-resistance genes during infection, make temperate phages unsuitable for therapeutic purposes. It has been reported that free-living and virulent $S$. aureus phages in the environment are relatively low in numbers compared with phages infecting other bacterial species, although some virulent phages have been found in S. aureus [1719]. Therefore, we examined the potency of two of the broad host range lytic staphylococcal phages, namely $\mathrm{K}$ and 44AHJD, belonging to the families Myoviridae and Podoviridae, respectively. Complete nucleotide sequences for both of these phages have been reported previously $[20,21]$.

Among 16 studied staphylococcal phages, 44AHJD is highly virulent because of the high translation efficiency of many of its genes [18], making it a good candidate for a therapeutic anti-bacterial agent. Several phase I studies with bacteriophages have been published [22-24], using phages that have obtained Generally Regarded As Safe (GRAS) status by the US Food and Drug Administration (FDA). In 2009, a US FDA-approved bacteriophage Phase I clinical trial was reported, evaluating a bacteriophage cocktail targeting S. aureus, Pseudomonas aeruginosa, and Escherichia coli in venous ulcers [25]. A phage product for controlling Listeria monocytogenes in readyto-eat meat and cheese represents acceptance of phages among regulated antibacterials [26].

In the present study, we purified phages K and 44AHJD by ammonium sulphate precipitation, followed by ionexchange chromatography. The levels of contaminating host proteins and endotoxins were determined and compared with phages purified by conventional cesium chloride $(\mathrm{CsCl})$ density gradient centrifugation. Purified phages in the form of a cocktail were then evaluated for their in vivo efficacy in an experimental S. aureus nasal colonization mouse model.

\section{Materials and Methods}

\subsection{Bacterial Strains and Bacteriophages}

Eighty-six S. aureus isolates, comprising 27 MRSA and 23 MSSA strains collected from hospitals in and around Bangalore, India, and 36 global strains (33 MRSA and 3 MSSA), were used to assess the bactericidal activity of the two virulent staphylococcal phages, $\mathrm{K}$ and 44AHJD (GenBank accession numbers AY176327 and AF513032 respectively). Thirty distinct, typed isolates of global representation were obtained from the Public Health Research Institute (PHRI), New Jersey, USA. Phage K (NC07814-02) was obtained from the Health Protection Agency Culture Collections, UK, and phage 44AHJD was a gift from Dr. Udo Blaesi, University of Vienna, Austria. All strains were cultured in Luria-Bertani (LB) broth at $37^{\circ} \mathrm{C}$ on a rotary shaker (200 rpm), unless otherwise stated. S. aureus strain Newman was used in the in vivo experiments. Polyclonal antibody for $S$. aureus RN4220 was generated at Raj Biotech, Pune, India.

\subsection{Bacteriophage Propagation, Enumeration, and Host Range Determination}

Phages $\mathrm{K}$ and 44AHJD were amplified in S. aureus strains RN4220 and KB600, as described previously [27]. Briefly, the propagating hosts were grown at $37^{\circ} \mathrm{C}$ in $\mathrm{LB}$ broth to an absorbance at $600 \mathrm{~nm}$ of $\sim 0.8$ and then infected with the respective phages at a MOI of 0.1 and further incubated for $4 \mathrm{~h}$. Phage was harvested following centrifugation of the culture lysate at $3000 \times \mathrm{g}$ for $10 \mathrm{~min}$ to remove the cell debris. The supernatant was filtered through a $0.2 \mu \mathrm{m}$ filter and the phage titer was determined. No viable bacteria were detected in the phage preparations. Phage plaques were enumerated and titers were determined using an agar overlay method [28]. The sterile phage solutions were stored at $4^{\circ} \mathrm{C}$, and no decrease in the phage titer was observed during the study period, as assessed by plaque assay using suitable indicator cells.

\subsection{Phage Purification}

Phage K crude lysate was precipitated using solid ammonium sulfate fractionation from $0 \%-30 \%$ and $30 \%$ $70 \%$ ammonium sulfate at room temperature, and then centrifuged at $12,860 \times \mathrm{g}$ for $45 \mathrm{~min}$ at $4^{\circ} \mathrm{C}$. The pellet obtained from the $30 \%-70 \%$ fraction was dialyzed against $25 \mathrm{mM}$ Tris- $\mathrm{Cl} \mathrm{pH} 7.5$ (buffer A) overnight. The dialyzed material was loaded onto a weak anion exchange DEAE cellulose (DE52) column (Whatman Inc., Florham Park, NJ, USA) using a Biologic Duoflo system (Bio-Rad, Hercules, CA, USA) equilibrated with buffer $A$ at a flow rate of $5 \mathrm{~mL} / \mathrm{min}$. The column was washed with buffer A until the absorbance of the eluting fractions at $280 \mathrm{~nm}$ was zero. The bound phages were recovered by isocratic elution with $0.2 \mathrm{M} \mathrm{NaCl}$ in buffer A, dialyzed against buffer A, filter-sterilized through a $0.2 \mu \mathrm{m}$ filter, and then analyzed by SDS-PAGE followed by silver staining. A similar protocol was followed for phage 44AHJD crude lysate.

Phages were enumerated from all of the chromatographic fractions, and percent phage recoveries were cal- 
culated taking the initial material as $100 \%$.

\subsection{Purification by $\mathrm{CsCl}$ Ultracentrifugation}

One liter each of phage $\mathrm{K}$ and 44AHJD lysate was centrifuged at $25,000 \times \mathrm{g}$ for $2 \mathrm{~h}$ at $4^{\circ} \mathrm{C}$. The pellet, containing bacteriophage particles, was resuspended in approximately $1 \mathrm{~mL}$ of buffer $\mathrm{A}$. $\mathrm{CsCl}$ density gradient ultracentrifugation of this phage concentrate was performed following standard methods [29]. The density of $\mathrm{CsCl}$ used ranged from $1.81-1.27 \mathrm{~g} \cdot \mathrm{L}^{-1}$. The bacteriophages banded at a $\mathrm{CsCl}$ density of $1.54-1.40 \mathrm{~g} \cdot \mathrm{L}^{-1}$, and were recovered by careful siphoning. This fraction was dialyzed against buffer $\mathrm{A}$ to remove $\mathrm{CsCl}$, and then filtersterilized.

\subsection{Protein Analyses and Endotoxin Content of Phage Preparations}

Protein content at different stages of phage purification was determined according to the method of Lowry et al. (1951) [30], using bovine serum albumin (BSA) as standard. Protein profiles of phage preparations were analyzed by SDS-PAGE on $12 \%$ gels and visualized by silver staining.

The endotoxin content of the phage preparations was measured using an Endosafe Rapid LAL reagent kit (Charles River, Wilmington, MA, USA).

\subsection{Experimental Murine Nasal Colonization Model}

\subsubsection{Animals}

Healthy 6-week-old BALB/c mice (National Institute of Nutrition, Hyderabad, India) were used in all experiments. Animal experiments were performed at St. John's Medical College and Hospital, Bangalore, India. The experiments were approved by the Institutional Animal Ethics Committee (IAEC) and the Committee for the Purpose of Control and Supervision of Experiments on Animals (CPCSEA). St. John's Medical College is registered with CPCSEA (Registration No. 90/1999/CPCSEA dated 28/ 4/1999).

\subsubsection{Evaluation of Commensal Nasal Flora of Mice}

The commensal nasal flora of the mice was evaluated by nasal swabbing as described previously [31]. After nasal sampling, the swabs were placed in $150 \mu \mathrm{L}$ of sterile $0.85 \% \mathrm{NaCl}$ in microfuge tubes. Tubes were thoroughly vortexed and the supernatant along with the swabs were plated on nutrient agar containing 5\% sheep blood. Staphylococcal colonies were identified based on morphology and biochemical characteristics (HiStaph Identification kit, HiMedia, Mumbai, India), and confirmed using an S. aureus-specific ELISA.

\subsubsection{Determination of $S$. aureus Newman Colonization Rate}

Mice were administered chloramphenicol sodium succinate at $0.5 \mathrm{mg} / \mathrm{mL}$ in drinking water, beginning at $24 \mathrm{~h}$ prior to inoculation of challenge strain, which continued until the end of the study.

Chloramphenicol-resistant S. aureus strain Newman was grown at $37^{\circ} \mathrm{C}$ overnight on Columbia agar containing $2 \% \mathrm{NaCl}$ to induce capsule formation [32]. The culture was harvested in sterile PBS, then centrifuged at $5800 \times \mathrm{g}$ for $10 \mathrm{~min}$ and resuspended in sterile PBS at $5 \times$ $10^{7} \mathrm{CFU} \cdot \mu \mathrm{L}^{-1}$, for nasal inoculation. Groups of mice were anaesthetized by intraperitoneal injection of ketamine $\left(90 \mathrm{mg} \cdot \mathrm{kg}^{-1}\right.$ body weight) and xylazine $\left(9 \mathrm{mg} \cdot \mathrm{kg}^{-1}\right.$ body weight). Ten microliters of $S$. aureus cell suspension was inoculated into the nares of all animals on day 1 . Subsets of mice were euthanized by anesthetic overdose on days 7, 10, and 14 post-inoculation. The nasal tissue was excised and processed for quantitative evaluation of colonization in such a way that the skin around the nares was removed prior to dissection as described by Kiser et al. [32]. The suspension was briefly centrifuged to settle the particulate tissue and the supernatant was cultured overnight at $37^{\circ} \mathrm{C}$ on LB agar containing chloramphenicol $(34 \mu \mathrm{g} / \mathrm{mL})$. The resulting chloramphenicol-resistant colonies were enumerated. Representative colonies from each presumptive $S$. aureus Newman positive animal were purified on LB agar for confirmation by ELISA.

\subsubsection{Evaluation of Phage Efficacy in Vivo}

Three groups of mice $(n=8)$ were used for the study. These were colonized with the challenge strain as described in 3.8. Daily doses of phage cocktail containing $1 \times$ $10^{10}$ PFU of phage $\mathrm{K}$ and $4 \times 10^{10}$ PFU of phage 44AHJD in $10 \mu \mathrm{L}$ of $0.85 \% \mathrm{NaCl}$ were administered intranasally to the test group on days 5,6 , and 7 . The placebo control group was administered $10 \mu \mathrm{L}$ of $0.85 \%$ $\mathrm{NaCl}$. On day 8 , the mice were euthanized and nasal tissue was taken for confirmation and enumeration of the test strain, as described above.

\subsubsection{ELISA and Western Blot Studies}

ELISA for detection of $S$. aureus derived proteins and $S$. aureus confirmation was performed using polyclonal antibodies generated for the $S$. aureus host RN4220 cell lysate. Dilutions of the RN4220 host lysate (from $1 \mathrm{ng}$ to $1000 \mathrm{ng}$ protein) served as the antigen, and were used for construction of a standard curve.

For western blot studies, all samples were run on a $12.5 \%$ SDS-PAGE gel and then transferred to a Biotrace nitrocellulose blotting membrane (Pall Corporation, Pensacola, FL, USA) and blocked with 3\% BSA (in Tris-Cl, $\mathrm{pH}$ 8.0, buffered saline with 0.1\% Tween 80:1 $\times$ TBST) overnight. Following washing with $1 \times$ TBST, primary 
anti-RN4220 antibody (final concentration: 1:5000) was added, and the membrane washed again with $1 \times$ TBST. Secondary goat anti-rabbit alkaline phosphatase (ALP) conjugate (final concentration: 1:500) was then added. The blot was developed using 5-bromo-4-chloro-3-indolyl-phosphate (BCIP) substrate in conjunction with NBT (nitro blue tetrazolium).

For identification of isolates from the mouse nares, colonies taken from pure isolates from LB agar were suspended in $0.05 \mathrm{M}$ carbonate-bicarbonate buffer $\mathrm{pH}$ 9.6, to a cell density of $-1 \times 10^{9} \mathrm{CFU} / \mathrm{mL}$. Two hundred microliters of this cell suspension were used to coat 96-well plates overnight at $4^{\circ} \mathrm{C}$. Wells were washed with TBST and blocked with $200 \mu \mathrm{L}$ of $1 \%$ BSA in TBST for $1 \mathrm{~h}$ at $37^{\circ} \mathrm{C}$. After repeated washes with TBST, $100 \mu \mathrm{L}$ of rabbit polyclonal anti-RN4220 antisera $(1: 20,000)$ was added and plates incubated for $1 \mathrm{~h}$ at $37^{\circ} \mathrm{C}$. Wells were washed again with TBST prior to addition of $100 \mu \mathrm{L}$ of ALP-labeled goat anti-rabbit antibody (1:5000). Plates were incubated for $1 \mathrm{~h}$ at $37^{\circ} \mathrm{C}$. Following washing of the wells, $100 \mu \mathrm{L}$ of substrate (PNPP) was added and plates were incubated for $40 \mathrm{~min}$, after which absorbance was read at $405 \mathrm{~nm}$.

\section{Results and Discussion}

\subsection{Bacteriophage Amplification, Enumeration and Host Range Determination}

While phage $\mathrm{K}$ was propagated using RN4220 as a propagating host, phage 44AHJD was propagated using KB600 host since we have earlier observed that 44AHJD requires endolysin supplementation for propagation in RN4220 [27]. Both the phages were amplified to a titer of $-1 \times 10^{10} \mathrm{PFU} / \mathrm{mL}$ in bioreactors using the protocol described earlier [27] and the host range of both the phages were assessed on a panel of Staphylococcus aureus isolates that included both MSSA and MRSA.

A total of 86 isolates were tested for phage sensitivity, which included 30 distinct typed $S$. aureus isolates of global representation; six of Community acquired (CA)-
MRSA type strains and 50 clinical isolates from Indian hospitals (data not shown). Nearly $57 \%$ of isolates were susceptible to phage $\mathrm{K}$ and phage $44 \mathrm{AHJD}$ was lytic to $86 \%$ of the isolates tested. In case of both phages taken together, $74.4 \%$ of isolates were sensitive with plaque formation. In total, $88.3 \%$ isolates were susceptible to both phages in combination (Table 1).

It has been shown earlier that a phage cocktail significantly reduces the frequency of mutation in bacteria in comparison to the use of a single phage preparation [33]. Therefore, a greater chance of successful treatment of bacterial infections may be expected by combining multiple phages with varied host specificities.

Due to its polyvalent nature, Staphylococcus phage K, has been studied in multiple applications, including in the treatment of subclinical bovine mastitis [34] and as an anti-staphylococcal hand-wash solution [35]. Here, we examined phage $\mathrm{K}$ alone, and together with 44AHJD as a cocktail, for activity against $S$. aureus isolates that represented highly virulent, antibiotic-resistant, and genetically diverse strains. This established that the therapeutic potential of phages is improved as part of a cocktail, which supports previous literature reports $[33,36]$.

\subsection{Phage Purification}

The recovery of phage $\mathrm{K}$ at various purification steps is summarized in Table 2, and the sodium dodecyl sulfatepolyacrylamide gel electrophoresis (SDS-PAGE) profile of purified phage $\mathrm{K}$ is compared with the cesium chloride-purified phage $\mathrm{K}$ in Figure 1.

The total recovered phage titer following ammonium sulfate precipitation was $32 \%$, with an almost eight-fold reduction in the total protein content.

Following anion exchange chromatography, the recovery was $31 \%$, with enhanced specific activity (Table 2). The SDS-PAGE profile of purified phage $K$ was comparable to the $\mathrm{CsCl}$ gradient-purified phage $\mathrm{K}$ (Figure 1). A recovery rate of almost $23 \%$ was achieved for purified phage 44AHJD using the ammonium sulfate

Table 1. Susceptibility of $S$. aureus isolates to phages.

\begin{tabular}{|c|c|c|c|c|c|c|c|c|c|c|c|c|}
\hline \multirow{3}{*}{ Phage sensitivity } & \multicolumn{4}{|c|}{ Phage K } & \multicolumn{4}{|c|}{ Phage 44AHJD } & \multicolumn{4}{|c|}{ Phage K + Phage 44AHJD } \\
\hline & \multicolumn{2}{|c|}{ Panel A } & \multicolumn{2}{|c|}{ Panel B } & \multicolumn{2}{|c|}{ Panel A } & \multicolumn{2}{|c|}{ Panel B } & \multicolumn{2}{|c|}{ Panel A } & \multicolumn{2}{|c|}{ Panel B } \\
\hline & $\begin{array}{l}\text { MRSA } \\
(27)\end{array}$ & $\begin{array}{l}\text { MSSA } \\
(23)\end{array}$ & $\begin{array}{c}\text { MRSA } \\
(33)\end{array}$ & $\begin{array}{l}\text { MSSA } \\
(3)\end{array}$ & $\begin{array}{l}\text { MRSA } \\
(27)\end{array}$ & $\begin{array}{l}\text { MSSA } \\
(23)\end{array}$ & $\begin{array}{c}\text { MRSA } \\
(33)\end{array}$ & $\begin{array}{l}\text { MSSA } \\
(3)\end{array}$ & $\begin{array}{l}\text { MRSA } \\
(27)\end{array}$ & $\begin{array}{l}\text { MSSA } \\
(23)\end{array}$ & $\begin{array}{l}\text { MRSA } \\
(33)\end{array}$ & $\begin{array}{c}\text { MSSA } \\
\text { (3) }\end{array}$ \\
\hline $\begin{array}{l}\text { Susceptible with } \\
\text { plaques }\end{array}$ & 3 & 9 & 26 & 3 & 14 & 9 & 30 & 3 & 15 & 14 & 32 & 3 \\
\hline $\begin{array}{l}\text { Susceptible due to lysis } \\
\text { from without }\end{array}$ & 1 & 0 & 7 & 0 & 8 & 8 & 2 & 0 & 7 & 4 & 1 & 0 \\
\hline Resistant & 23 & 14 & 0 & 0 & 5 & 6 & 1 & 0 & 5 & 5 & 0 & 0 \\
\hline
\end{tabular}

Panel A: S. aureus from India-27 MRSA and 23 MSSA category; Panel B: Global S. aureus panel including PHRI strains and USA type strains-33 MRSA and 3 MSSA category; ${ }^{*}$ Lysis seen due to lysis-from-without phenomenon due to phages at high MOI $(>100)$. 
precipitation/ion-exchange protocol (Table 3).

Purified phage particles have two major uses: phage biology studies and therapeutic applications. To date, most phage preparations for therapeutic use have been purified by passing the lysate through filters to remove the host bacteria. While such purification reduces the risk of bacterial infections, it does not remove bacterial endotoxins, which can be harmful to patients. Moreover, costeffective phage purification methods would be beneficial for large-scale production. Because the available literature describes phage purification using a variety of methods, including cesium chloride gradient ultracentrifugation [37], concentration by pelleting [18], monolithic

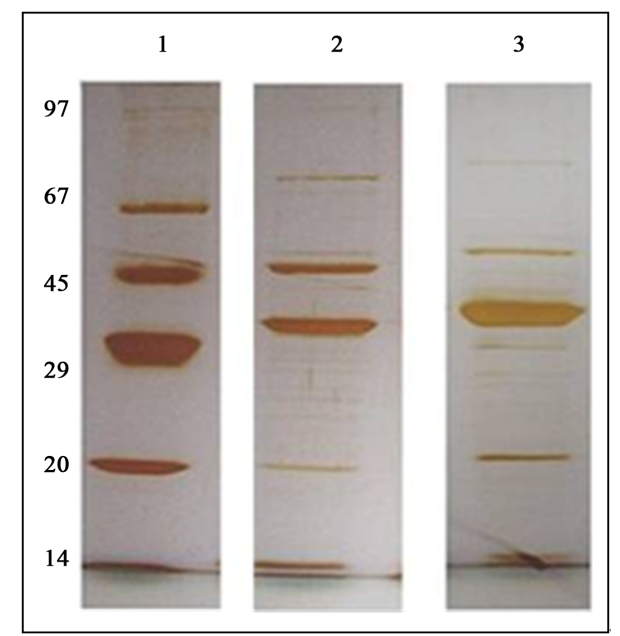

Figure 1. SDS-PAGE profile of purified phage $\mathrm{K}$ preparations. Lane 1, molecular weight marker (14 - $97 \mathrm{kDa})$; lane 2, phage $\mathrm{K}$ purified by $\mathrm{CsCl}$ gradient density ultracentrifugation; lane 3 , phage $\mathrm{K}$ purified by ion-exchange chromatography steps.

Table 2. Purification chart of phage $\mathrm{K}$.

\begin{tabular}{ccccc}
\hline Sample & $\begin{array}{c}\text { Total volume } \\
(\mathrm{mL})\end{array}$ & $\begin{array}{c}\text { Protein } \\
(\mathrm{mg} / \mathrm{mL})\end{array}$ & $\begin{array}{c}\text { Phage titer } \\
(\mathrm{PFU} / \mathrm{mL})\end{array}$ & \% yield \\
\hline 1 & 100 & 1.2 & $1.0 \times 10^{10}$ & 100 \\
2 & 4 & 4.0 & $8.0 \times 10^{10}$ & 32 \\
3 & 14 & 0.6 & $2.2 \times 10^{10}$ & 31 \\
\hline
\end{tabular}

Sample 1: Crude phage lysate; Sample 2: $30 \%$ - 70\% ammonium sulphate fraction; Sample 3: DEAE cellulose purified fraction.

Table 3. Purification chart of phage 44AHJD.

\begin{tabular}{ccccc}
\hline Sample & $\begin{array}{c}\text { Total volume } \\
(\mathrm{mL})\end{array}$ & $\begin{array}{c}\text { Protein } \\
(\mathrm{mg} / \mathrm{mL})\end{array}$ & $\begin{array}{c}\text { Phage titer } \\
(\mathrm{PFU} / \mathrm{mL})\end{array}$ & $\begin{array}{c}\% \\
\text { yield }\end{array}$ \\
\hline 1 & 500 & 12.0 & $3.4 \times 10^{11}$ & 100 \\
2 & 78 & 5.3 & $1.1 \times 10^{12}$ & 51 \\
3 & 1014 & 0.4 & $3.8 \times 10^{10}$ & 23 \\
\hline
\end{tabular}

Sample1: Crude phage lysate; Sample 2: 30\% - 70\% ammonium sulphate fraction; Sample 3: DEAE cellulose purified fraction. columns [38], size exclusion chromatography [39], and anion exchange chromatography [40], the yields achieved vary.

Phages purified by anion exchange methods have been used successfully in a number of human studies [38,41]. Therefore, the systematic approach for phage purification used in the current study would benefit researchers in this field.

The results of our assessment of the purity of bacteriophages obtained by SDS-PAGE (Figure 2) were similar to those reported previously for other phage types $[42,43]$. It was interesting to note that the SDS-PAGE profiles of the ion-exchange- and cesium chloride-purified phages were very similar.

\subsection{ELISA and Western Blot Studies}

The cesium chloride phage preparations and the phage cocktail preparation showed host cell contamination of $10-100 \mathrm{ng} / \mathrm{mL}$, as determined by ELISA with antiRN4220 antibodies. The western blot of samples from the $\mathrm{CsCl}$ and ion-exchange purified 44AHJD phages showed negligible signals for $S$. aureus host cell contaminants (Figure 3, lanes 1 and 7). Interestingly, the $16,000 \times$ g pelleted phage showed a significant amount of S. aureus host cell contamination (Figure 3, lane 2). Similar results were observed for phage K (data not shown).

The endotoxin levels of the phage cocktail used in our study was in the range as reported by other researchers [22]. Hence, the protocol described here for phage purification could be universally applicable. Production of such a phage cocktail in a facility following good manufacturing practices (GMP) would further reduce the endotoxin content, because it is well known that endotoxins

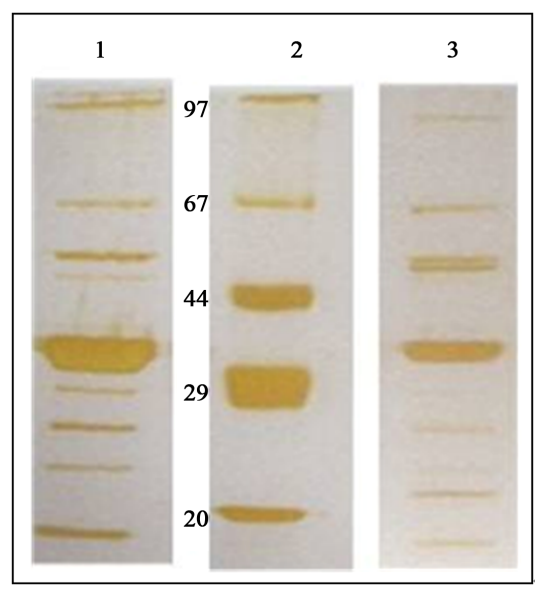

Figure 2. SDS-PAGE profile of purified phage 44AHJD preparations. Lane 1, phage 44AHJD purified by $\mathrm{CsCl}$ gradient density ultracentrifugation; lane 2 , molecular weight marker (14 - $97 \mathrm{kDa}$ ); lane 3, phage 44AHJD purified by ion-exchange chromatography. 


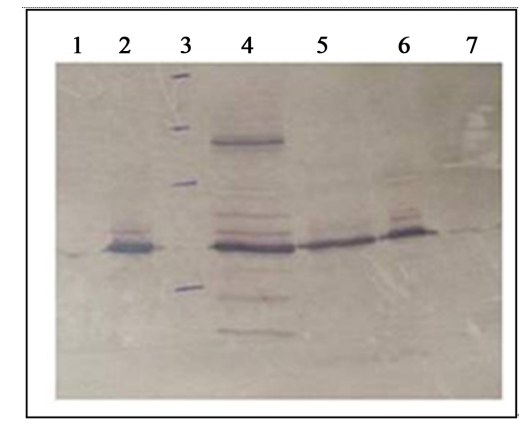

Figure 3. Western blot of phage 44AHJD samples. Lane 1, CsCl purified 44AHJD; lane 2, 16,000 $\times$ g pelleted phage; lane 3, marker (14 - $97 \mathrm{kDa})$; lane 4, S. aureus KB600 lysate; lane 5 , crude 44AHJD lysate; lane $6,30 \%-70 \%$ ammonium sulfate pellet; lane 7, DEAE cellulose (DE52) purified 44AHJD.

that bind to plastic and glass surfaces are efficiently removed by depyrogenation [44].

A recent report on purification of Staphylococcus phage VDX-10 showed that $>90 \%$ of host proteins were removed, which is similar to our observations [38].

\subsection{Evaluation of Commensal Nasal Flora}

Only coagulase-negative staphylococci (S. gallinarum, S. arlettae, and $S$. equorum) were found in BALB/c mice used for experimentation. S. aureus was not detected in any of the animals (data not shown).

\subsection{Determination of $S$. aureus Newman Colonization Rate in Mouse Nares}

Of the 24 mice nasally inoculated with $S$. aureus strain Newman, $83.3 \%$ were colonized on day 7 . On days 10 and $14,25 \%(2 / 8)$ and $12.5 \%(1 / 8)$ of mice remained colonized, respectively. The carriage rate of $S$. aureus Newman in the currently employed BALB/c mice is similar to reported earlier [32]. Based on this colonization profile, phage cocktail was applied nasally on days 5 7 post-inoculation with $S$. aureus.

\subsection{Evaluation of Phage Efficacy in Vivo}

The phage efficacy study involved evaluation of commensal bacterial flora from the mouse nares, then determination of the rate and extent of colonization of nasally inoculated S. aureus. Subsequently, efficacy of phage treatment was assessed in S. aureus-colonized mice. Phageeffected decolonization was evident in the animals treated with the phage cocktail. Daily doses of phage cocktail administered intranasally on days 5,6 , and 7 fully decolonized all eight animals inoculated with $S$. aureus strain Newman by day 8 while the colonization control group (seven of eight animals) and the group treated with placebo (six of eight animals) remained colonized (Fig- ure 4) during the experimental period. The number of CFU's recovered from the nares of the colonization control group ranged from 1 - $4 \mathrm{CFU} /$ nose while for the placebo treated, the CFU's recovered was in the range of 1 39 CFU/nose. No CFU's could be recovered from any of the animals of the phage treated group. The number of CFU's recovered from various groups of our present study correlates well with the literature reports of recovery of 1 - 300 CFU's of S. aureus Newman/nose of the $\mathrm{BALB} / \mathrm{c}$ mice [32].

S. aureus is not a normal commensal organism in mouse nares; therefore establishment of experimental colonization of $S$. aureus in these animals required optimization. We achieved sufficient maintenance of colonization to allow application of phage cocktail and test their efficacy. We found that $80 \%$ of mice remained colonized for 7 days in the model reported here. The mice were gradually decolonized of S. aureus naturally. Therefore, we chose a phage-treatment window within the 7day period and ended the study on day 8 . This afforded a good contrast between the treated and untreated groups. We observed decolonization of all animals in the treated group, while in the control group, $75 \%$ of animals remained colonized on day 8 . We believe this study to be the first report of bacteriophage efficacy in a mouse nasal model of $S$. aureus carriage.

It is well established that $S$. aureus colonizes multiple sites in the human body, particularly the anterior nares [45]. Approximately $20 \%$ of individuals are persistent carriers since they carry one type of $S$. aureus while a large population $(60 \%)$ harbor S. aureus transiently and $20 \%$ of the population never carry any Staphylococcus and are called as non-carriers [45]. It has been shown that a substantial proportion of serious nosocomial infections originate from the patient's own flora, and nasal carriage of $S$. aureus is a considerable risk factor for this $[45,46]$. Hence, elimination of carriage reduces the infection rates

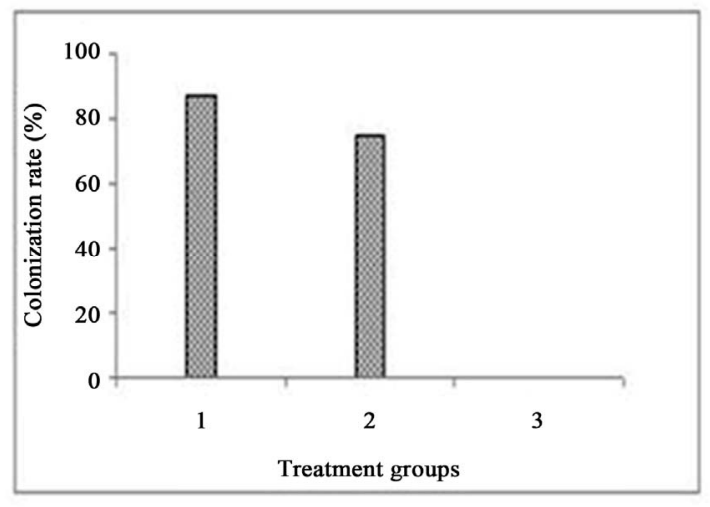

Figure 4. In vivo efficacy of phages 44AHJD and $K$ at the end of eight day. Treatment group no. 1: colonization control; treatment group no. 2: placebo treated; treatment group no. 3: phage cocktail treated. 
in surgical patients and those on hemodialysis and continuous ambulatory peritoneal dialysis (CAPD) [45]. Higher incidence of such organisms is also reported in the Indian community [47]. There is also compelling genetic evidence that there is a causal relationship between nasal carriage and infective clinical isolates [48]. In light of these observations, it appears that eradication of $S$. aureus during hospitalization would be valuable [49].

As there are no current guidelines on the bacteriophage titer that may be clinically effective against MRSA in the human nose, estimates can be made based on previous related studies of bacteriophage therapy. These include use of bacteriophage titers in respirable powders $\left(10^{8}-10^{9}\right.$ PFU per $100 \mathrm{mg}$ powder) [49], and in bacteriophages targeting $P$. aeruginosa in otitis in humans ( $10^{5}$ PFU of each of six bacteriophages in $0.2 \mathrm{~mL}$ liquid) [50]. Based on these two studies, $10^{10}$ PFU per mouse nare is likely to be an optimal dose.

Use of bacteriophages for treatment of various bacterial infections including $S$. aureus has been reviewed extensively [51,52]. Although temperate phages of $S$. aureus are more widely known $[53,54]$, due to the potential problems of lysogeny and toxic gene transfer, its therapeutic use is limited [55]. Hence, the present article on efficacy of two lytic bacteriophages of staphylococcus namely Phage $\mathrm{K}$ and 44AHJD on nasal decolonization of Staphylococcus aureus in mice nares is relevant and valuable.

\section{Acknowledgements}

The authors thank Dr. Barry Kreiswirth, PHRI, New Jersey, for the gift of clinical isolates, and Dr. Richard Novick for $S$. aureus strain RN4220. Thanks are also due to Dr. Udo Blaesi, University of Vienna, for the gift of phage 44AHJD, and Dr. Kenneth Bayles, Nebraska Medical Center, for $S$. aureus strain KB600. The authors thank Dr. Sudha Suresh, Pharmacology Division of St. John's Medical College and Hospital, Bangalore, for assistance with animal experiments. The authors acknowledge Dr. Janakiraman Ramachandran, Chairman \& CEO, Gangagen Inc, USA, for his support and encouragement, and Dr. M. Jayasheela, Head of Clinical Development and Regulatory Affairs, Gangagen Biotechnologies Pvt. Ltd., Bangalore, India. The authors acknowledge the upstream process development team for providing phage lysate for purification studies used in this work, and $\mathrm{Mr}$. Naveen Kumar for formatting one of the figures in this paper.

\section{REFERENCES}

[1] T. L. Bannerman and S. J. Peacock, "Staphylococcus, Micrococcus, and Other Catalase-Positive Cocci," In: P. R.
Baron, E. J. Jorgensen, J. H. Landry, M. L. Pfaller and M. A. Murray, Eds., Manual of Clinical Microbiology, ASM Press, Washington DC, 2007, pp. 384-404.

[2] G. Lina, Y. Piémont, F. Godail-Gamot, M. Bes, M. O. Peter, V. Gauduchon, F. Vandenesch and J. Etienne, "Involvement of Panton-Valentine Leukocidin Producing Staphylococcus aureus in Primary Skin Infections and Pneumonia," Clinical Infectious Diseases, Vol. 29, No. 5, 1999, pp. 1128-1132. doi:10.1086/313461

[3] A. L. Casey, P. A. Lambert and T. S. J. Elliott, "Staphylococci," Journal of Antimicrobial Agents, Vol. 29, No. 3, 2007, pp. S23-S32. doi:10.1016/S0924-8579(07)72175-1

[4] P. A. C. Maple, J. M. T. Hamilton-Miller and W. Brumfitt, "World-Wide Antibiotic Resistance in MethicillinResistant Staphylococcus aureus," The Lancet, Vol. 333, No. 8637,1989 , pp. 537-540. doi:10.1016/S0140-6736(89)90076-7

[5] H. L. Evans and R. G. Saywer, "Cycling Chemotherapy: A Promising Approach to Reducing the Morbidity and Mortality of Nosocomial Infections," Drugs Today, Vol. 39, No. 9, 2003, pp. 733-738. doi: $10.1358 /$ dot.2003.39.9.799480

[6] J. C. Gould, J. H. Smith and H. Moncur, "Mupirocin in General Practice: A Placebo Controlled Trial. In: D. S. Wilkinson and J. D. Price, Eds., International Congress and Symposium Series, Mupirocin-A Novel Topical Antibiotic, Royal Society of Medicine, London, 1984, pp. 85-93.

[7] T. Coates, R. Bax and A. Coates, "Nasal Decolonization of Staphylococcus aureus with Mupirocin: Strengths, Weaknesses and Future Prospects," Journal of Antimicrobial Chemotherapy, Vol. 64, No. 1, 2009, pp. 9-15.

[8] S. Fujimura and A. Watanabe, "Survey of High- and LowLevel Mupirocin-Resistant Strains of Methicillin-Resistant Staphylococcus aureus in 15 Japanese Hospitals," Chemotherapy, Vol. 49, No. 1-2, 2003, pp. 36-38. doi:10.1159/000069780

[9] L. Djouhri-Bouktab, K. Alhanout, V. Andrieu, D. Raoult, J. M. Rolain and J. M. Brunel, "Squalamine Ointment for Staphylococcus aureus Skin Decolonization in a Mouse Model," Journal of Antimicrobial Chemotherapy, Vol. 66, No. 6, 2011, pp. 1306-1310.

[10] T. Iwase, Y. Uehara, H. Shinji, A. Tajima, H. Seo, K. Takada, T. Agata and Y. Mizunoe, "Staphylococcus epidermidis Esp inhibits Staphylococcus aureus Biofilm Formation and Nasal Colonization," Nature, Vol. 465, No. 7296, 2010, pp. 346-349. http://dx.doi.org/10.1038/nature09074PMid:20485435

[11] B. Park, T. Iwase and G. Y. Liu, "Intranasal Application of $S$. epidermidis Prevents Colonization by MethicillinResistant Staphylococcus aureus in Mice," PLOS ONE, Vol. 6, No. 10, 2011, p. e25880. doi:10.1371/journal.pone. 0025880

[12] T. K. Lu and J. J. Collins, "Dispersing Biofilms with Engineered Enzymatic Bacteriophage," Proceedings of $\mathrm{Na}$ tional Academy of Sciences USA, Vol. 104, No. 27, 2007, pp. 11197-11202. doi:10.1073/pnas.0704624104

[13] S. Chibani-Chennou, A. Bruttin, M.-L. Dillmann and H. Brussow, "Phage-Host Interaction: An Ecological Perspe- 
ctive," Journal of Bacteriology, Vol. 186, No. 12, 2004, pp. 3677-3686. doi:10.1128/JB.186.12.3677-3686.2004

[14] S. M. Shasha, N. Sharon and M. Inbar, "Bacteriophages as Antibacterial Agents," Harefuah, Vol. 143, No. 2, 2004, pp. 121-125.

[15] B. Weber-Dabrowska, M. Mulczyk and A. Górski, "Bacteriophage Therapy of Bacterial Infections: An Update of Our Institute's Experience," Archives of Immunological Therapies and Experiments (Warsz), Vol. 48, No. 6, 2000, pp. 547-551.

[16] D. Kelly, O. McAuliffe, R. P. Ross, J. O’Mahony and A. Coffey, "Development of a Broad-Host-Range Phage Cocktail for Biocontrol," Bioengineered Bugs, Vol. 4, No. 2, 2011, pp. 31-37. doi:10.4161/bbug.2.1.13657

[17] A. J. Synnott, Y. Kuang, M. Kurimoto, K. Yamamichi, H. Iwano and Y. Tanji, "Isolation from Sewage Influent and Characterization of Novel Staphylococcus aureus Bacteriophages with Wide Host Ranges and Potent Lytic Capabilities," Applied and Environmental Microbiology, Vol. 75, No. 13, 2009, pp. 4483-4490. doi:10.1128/AEM.02641-08

[18] K. Sau, S. K. Gupta, S. Sau and T. C. Ghosh, "Synonymous Codon Usage Bias in 16 Staphylococcus aureus Phages: Implication in Phage Therapy," Virus Research, Vol. 113, No. 2, 2005, pp. 123-131. doi:10.1016/j.virusres.2005.05.001

[19] H. Hoshiba, J. Uchiyama, S.-I. Kato, T. Ujihara, A. Muraoka, M. Daibata, H. Wakiguchi and S. Matsuzaki, "Isolation and Characterization of a Novel Staphylococcus aureus Bacteriophage, ØMR25, and Its Therapeutic Potential," Archives of Virology, Vol. 155, No. 4, 2010, pp. 545552. doi:10.1007/s00705-010-0623-2

[20] S. O'Flaherty, A. Coffey, R. Edwards, W. Meaney, G. F. Fitzgerald and R. P. Ross, "Genome of Staphylococcal Phage K: A New Lineage of Myoviridae Infecting GramPositive Bacteria with a Low G + C Content," Journal of Bacteriology, Vol. 186, No. 9, 2004, pp. 2862-2871. doi:10.1128/JB.186.9.2862-2871.2004

[21] D. Vybiral, M. Takac, M. Loessner, A. Witte, U. von Ahsen and U. Blasi, "Complete Nucleotide Sequence and Molecular Characterization of Two Lytic Staphylococcus aureus Phages: 44AHJD and P68," FEMS Microbiology Letters, Vol. 219, No. 2, 2003, pp. 275-283. doi:10.1016/S0378-1097(03)00028-4

[22] A. Bruttin and B. Brussow, "Human Volunteers Receiving Escherichia coli Phage T4 Orally: A Safety Test of Phage Therapy," Antimicrobial Agents and Chemotherapy, Vol. 49, No. 7, 2005, pp. 2874-2878. doi:10.1128/AAC.49.7.2874-2878.2005

[23] M. Merabishvili, J. P. Pirnay, G. Verbeken, N. Chanishvili, M.Tediashvili, N. Lashkhi, T. Glonti, V. Krylov, J. Mast, L. V. Parys, R. Lavigne, G. Volckaert, W. Mattheus, G. Verveen, P. De Corte, T. Rose, S. Jennes, M. Zizi, D. De Vos and M. Vaneechoutte, "Quality-Controlled SmallScale Production of a Well-Defined Bacteriophage Cocktail for Use in Human Clinical Trials," PLos ONE, Vol. 4, No. 3, 2009, p. e4944. doi:10.1371/journal.pone.0004944

[24] A. Wright, C. H. Hawkins, E. E. Anggård and D. R. Harper, "A Controlled Clinical Trial of a Therapeutic Bacte- riophage Preparation in Chronic Otitis Due to Antibiotic-Resistant Pseudomonas aeruginosa-A Preliminary Report of Efficacy," Clinical Otolaryngology, Vol. 34, No. 4, 2009, pp. 349-357.

doi:10.1111/j.1749-4486.2009.01973.x

[25] D. D. Rhoads, R. D. Wolcott, M. A. Kuskowski, B. M. Wolcott, L. S. Ward and A. Sulakvelidze, "Bacteriophage Therapy of Venous Leg Ulcers in Humans: Results of a Phase I Safety Trial," Journal of Wound Care, Vol. 18, No. 6, 2009, pp. 237-243.

[26] S. Guenther, D. Huwyler, S. Richard and M. J. Loessner, "Virulent Bacteriophage for Efficient Biocontrol of Listeria monocytogenes in Ready-to-Eat Foods," Applied and Environmental Microbiology, Vol. 75, No. 1, 2009, pp. 93-100. doi:10.1128/AEM.01711-08

[27] K. G. P. Nirmal, S. Sudarson, V. D. Paul, S. Nandini, S. R. Sanjeev, S. Hariharan, B. Sriram and S. Padmanabhan, "Use of Prophage Free Host for Achieving Homogenous Population of Bacteriophages: New Findings," Virus Research, Vol. 169, No. 1, 2012, pp. 182-187. doi:10.1016/j.virusres.2012.07.026

[28] B. Anderson, M. H. Rashid, C. Carter, G. Pasternack, C. Rajanna, T. Revazishvili, T. Dean, A. Senecal and A. Sulakvelidze, "Enumeration of Bacteriophage Particles. Comparative Analysis of the Traditional Plaque Assay and Real-Time QPCR- and Nanosight-Based Assays," Bacteriophage, Vol. 1, No. 2, 2011, pp. 86-93. doi:10.4161/bact.1.2.15456

[29] J. Sambrook, A. Fritsch and T. Maniatis, "Bacteriophage Lambda and Its Vectors," In: N. Ford and C. Nolan, Eds., Molecular Cloning: A Laboratory Manual, 3rd Edition, Cold Spring Harbor Laboratory Press, Cold Spring Harbor, 1989, pp. 2.1-2.117.

[30] O. H. Lowry, N. J. Rosenbrough, A. L. Farr and R. J. Randall, "Protein Measurement with Folin Phenol Reagent," Journal of Biological Chemistry, Vol. 193, No. 1, 1951, pp. 265-275.

[31] M. S. Rouse, M. Rotger, K. E. Piper, J. M. Steckelberg, M. Scholz, J. Andrews and R. Patel, "In Vitro and in Vivo Evaluations of the Activities of Lauric Acid Monoester Formulations against Staphylococcus aureus," Antimicrobial Agents Chemotherapy, Vol. 49, No. 8, 2005, pp. 3187 3191. doi:10.1128/AAC.49.8.3187-3191.2005

[32] K. B. Kiser, J. M. Cantey-Kiser and J. C. Lee, "Development and Characterization of a Staphylococcus aureus Nasal Colonization Model in Mice," Infection and Immunity, Vol. 67, No. 10, 1999, pp. 5001-5006.

[33] H. M. R. T. Parracho, B. H. Burrowes, M. C. Enright, M. L. McConville and D. R. Harper, "The Role of Regulated Clinical Trials in the Development of Bacteriophage Therapeutics," Journal of Molecular and Genetic Medicine, Vol. 6, 2012, pp. 279-286.

[34] J. J. Gill, J. C. Pacan, M. E. Carson, K. E. Leslie, M. W. Griffiths and P. M. Sabour, "Efficacy and Pharmacokinetics of Bacteriophage Therapy in Treatment of Subclinical Staphylococcus aureus Mastitis in Lactating Dairy Cattle," Antimicrobial Agents and Chemotherapy, Vol. 50, No. 9, 2006, pp. 2912-2918. doi:10.1128/AAC.01630-05

[35] S. O'Flaherty, R. P. Ross, W. Meaney, G. F. Fitzgerald, 
M. F. Elbreki and A. Coffey, "Potential of the Polyvalent Anti-Staphylococcus Bacteriophage K for Control of Antibiotic-Resistant Staphylococci from Hospitals," Applied and Environmental Microbiology, Vol. 71, No. 4, 2005, pp. 1836-1842. doi:10.1128/AEM.71.4.1836-1842.2005

[36] J. Gu, X. Liu, Y. Li, W. Han, L. Lei, Y. Yang, H. Zhao, Y. Gao, J. Song, R. Lu, C. Sun and X. Feng, "A Method for Generation of Phage Cocktail with Great Therapeutic Potential," PLoS ONE, Vol. 7, No. 3, 2012, pp. 1-8. doi:10.1371/journal.pone.0031698

[37] B. Biswas, S. Adhya, P. Washart, B. Paul, A. N. Trostel, B. Powell, R. Carlton and C. R. Merril, "Bacteriophage Therapy Rescues Mice Bacteremia from a Clinical Isolate of Vancomycin-Resistant Enterococcus faecium," Infection and Immunity, Vol. 70, No. 1, 2002, pp. 204-210. doi:10.1128/IAI.70.1.204-210.2002

[38] P. Kramberger, R. C. Honour, R. E. Herman F. Smrekar and M. Peterka, "Purification of the Staphylococcus aureus Bacteriophages VDX-10 on Methacrylate Monoliths," Journal of Virological Methods, Vol. 166, No. 1-2, 2010, pp. 60-64. doi:10.1016/j.jviromet.2010.02.020

[39] M. Y. Zakharova, A. V. Kozyr, A. N. Ignatova, I. A. Vinnikov, I. G. Shemyakin and A. V. Kolesnikov, "Purification of Filamentous Bacteriophage for Phage Display Using Size-Exclusion Chromatography," BioTechniques, Vol. 38, No. 2, 2005, pp. 194-198. doi:10.2144/05382BM04

[40] J. W. Uhr, M. S. Finkelstein and J. B. Baumann, “Antibody Formation: III. The Primary and Secondary Antibody Response to Bacteriophage øX 174 in Guinea Pigs," Journal of Experimental Medicine, Vol. 115, No. 3, 1962, pp. 655-670. doi:10.1084/jem.115.3.655

[41] H. D. Ochs, S. D. Davis and R. J. Wedgwood, "Immunologic Responses to Bacteriophage $ø \mathrm{X} 174$ in Immunodeficiency Diseases," Journal of Clinical Investigation, Vol. 50, No. 12, 1971, pp. 2559-2568. doi:10.1172/JCI106756

[42] R. Monjezi, B. T. Tey, C. C. Sieo and W. S. Tan, "Purification of Bacteriophage M13 by Anion Exchange Chromatography," Journal of Chromatography B. Analytical Technologies in the Biomedical and Life Sciences, Vol. 878, No. 21, 2010, pp. 1855-1859. doi:10.1016/i.jchromb.2010.05.028

[43] A. A. Elshayeb, S. O. Yagoub, A. S. Yousif, E. A. Abedalkareem, S. M. E. Hag and A. A. Elagib, "Identification of Protein Profiles of Escherichia coli, Staphylococcus aureus and Their Corresponding Phages," American Journal of Biotechnology and Molecular Sciences, Vol. 1, No. 2, 2011, pp. 39-44. doi:10.5251/ajbms.2011.1.2.39.44

[44] P. F. Roslansky, M. E. Dawson and T. J. Novitsky, "Plastics, Endotoxins, and the Limulus Amebocyte Lysate Test," Journal of Parenteral Science and Technology, Vol. 45, No. 2, 1991, pp. 83-87.

[45] J. Kluytmans, A. VanBelkum and H. Verbrugh, "Nasal Carriage of Staphylococcus aureus: Epidemiology, Underlying Mechanisms, and Associated Risks," Clinical
Microbiology Reviews, Vol. 10, No. 3, 1997, pp. 505-520.

[46] M. Fenton, P. G. Casey, C. Hill, C. G. M. Gahan, R. P. Ross, O. McAuliffe, J. O'Mahony, F. Maher and A. Coffey, "The Truncated Phage Lysin CHAPk Eliminates Staphylococcus aureus in the Nares of Mice," Bioenginneered Bugs, Vol. 1, No. 6, 2010, pp. 404-407.

doi:10.4161/bbug.1.6.13422

[47] S. S. Chatterjee, P. Ray, A. Agarwal, A. Das and M. Sharma, "A Community-Based Study on Nasal Carriage of Staphylococcus aureus," Indian Journal of Medical Research, Vol. 130, No. 6, 2009, pp. 742-748.

[48] R. P. Lamers, J. W. Stinnett, G. Muthukrishnan, C. L. Parkinson and A. M. Cole, "Evolutionary Analyses of Staphylococcus aureus Identify Genetic Relationships Between Nasal Carriage and Clinical Isolates," PLOS ONE, Vol. 6, No. 1, 2011, p. e16426. doi:10.1371/journal.pone.0016426

[49] M. Alfadhela, U. Puapermpoonsiria, S. J. Fordb, F. J. McInnesa and C. F. van der Walle, "Lyophilized Inserts for Nasal Administration Harboring Bacteriophage Selective for Staphylococcus aureus: In Vitro Evaluation," International Journal of Pharmaceutics, Vol. 416, No. 1, 2011, pp. 280-287. doi:10.1016/j.ijpharm.2011.07.006

[50] L. Golshahi, K. D. Seed, J. J. Dennis and W. H. Finlay, "Towards Modern Inhalational Bacteriophage Therapy: Nebulization of Bacteriophages of Burkholderia cepacia Complex," Journal of Aerosol Medicine and Pulmonary Drug Delivery, Vol. 21, No. 4, 2008, pp. 351-360. doi:10.1089/jamp.2008.0701

[51] S. Deresinski, "Bacteriophage Therapy: Exploiting Smaller Fleas," Clinical Infectious Diseases, Vol. 48, No. 8, 2009, pp. 1096-1101. doi:10.1086/597405

[52] P. A. Barrow and J. S. Soothill, "Bacteriophage Therapy and Prophylaxis: Rediscovery and Renewed Assessment of Potential," Trends in Microbiology, Vol. 5, No. 7, 1997, pp. 268-271. doi:10.1016/S0966-842X(97)01054-8

[53] V. D. Paul, S. Sundarrajan, S. S. Rajagopalan, S. Hariharan, N. Kempashanaiah, S. Padmanabhan, B. Sriram and J. Ramachandran, "Lysis-Deficient Phages as Novel Therapeutic Agents for Controlling Bacterial Infection," BMC Microbiology, Vol. 11, 2011, p. 195. doi:10.1186/1471-2180-11-195

[54] C. Goerke, R. Pantucek, S. Holtfreter, B. Schulte, M. Zink, D. Grumann, B. M. Bröker, J. Doskar and C. Wolz, "Diversity of Prophages in Dominant Staphylococcus aureus Clonal Lineages," Journal of Bacteriology, Vol. 191, No. 11, 2009, pp. 3462-3468. doi:10.1128/JB.01804-08

[55] D. C. Coleman, D. J. Sullivan, R. J. Russell, J. P. Arbuthnott, B. F. Carey and H. M. Pomeroy, "Staphylococcus aureus Bacteriophages Mediating the Simultaneous Lysogenic Conversion of Beta-Lysin, Staphylokinase and Enterotoxin A: Molecular Mechanism of Triple Conversion," Journal of General Microbiology, Vol. 135, No. 6, 1989, pp. 1679-1697. 